\title{
Observer-Based Sliding Mode Control for Stabilization of a Dynamic System with Delayed Output Feedback
}

\author{
Bo Wang, ${ }^{1,2}$ Peng Shi, ${ }^{3,4}$ Hamid Reza Karimi, ${ }^{5}$ and Cheng Chew Lim $^{3}$ \\ ${ }^{1}$ School of Applied Mathematics, University Electronic Science and Technology of China, Chengdu 610054, China \\ ${ }^{2}$ School of Electrical and Information Engineering, Xihua University, Chengdu 610096, China \\ ${ }^{3}$ School of Electrical and Electronic Engineering, The University of Adelaide, Adelaide, SA 5005, Australia \\ ${ }^{4}$ College of Engineering and Science, Victoria University, Melbourne, VIC 8001, Australia \\ ${ }^{5}$ Department of Engineering, Faculty of Engineering and Science, University of Agder, 4898 Grimstad, Norway
}

Correspondence should be addressed to Hamid Reza Karimi; hamid.r.karimi@uia.no

Received 10 July 2013; Accepted 29 August 2013

Academic Editor: Rongni Yang

Copyright (c) 2013 Bo Wang et al. This is an open access article distributed under the Creative Commons Attribution License, which permits unrestricted use, distribution, and reproduction in any medium, provided the original work is properly cited.

This paper considers the sliding mode control problem for a kind of dynamic delay system. First by utilizing Lyapunov stability theory and a linear matrix inequality technique, an observer based on delayed output feedback is constructed. Then, an integral sliding surface is presented to realize the sliding mode control for the system with the more available stability condition. Finally, some numerical simulations are implemented to demonstrate the validity of the proposed control method.

\section{Introduction}

For system control, state feedback control is a powerful tool when the full information of the system states is assumed to be accessible. However, in real engineering, not all of them can be available. Hence, the research on observer-based control system is a meaningful topic. Up to now, many relevant investigations [1-10] have been carried out. For instance, in [1], by imposing some restrictions on an open-loop system, two classes of the observer-based output feedback controllers, one finite dimensional and the other one infinite dimensional, are constructed; in [2], a static gain observer for linear continuous plants with intrinsic pulse-modulated feedback is designed to asymptotically drive the state estimation error to zero; in [3], by using the orthogonality-preserving numerical algorithm, a nonlinear discrete-time partial state observer is designed to realize the attitude determination for a kind of spacecraft system; in [4], with the two-step observation algorithms, an observer is constructed to force an underactuated aircraft to asymptotically track a given reference trajectory; in [5], through employing an adaptive backstepping approach, a modified high-gain observer is introduced to realize the global asymptotic tracking for a class of nonlinear systems.
In real engineering, time delays exist objectively, which makes the observer-based system control issue more complicated. Many existing control methods that have been well developed based on the conventional feedback observer, such as ones in [1-5], are not directly applicable. In addition, the LMI technique is known as a powerful tool for system control. However, it is not easy to use any more when time delays appear in the feedback output of system. Hence, the corresponding research is meaningful. Sliding mode control (SMC) has been proven to be an effective robust control strategy and has been successfully applied to a wide range of engineering systems such as spacecrafts, robot manipulators, aircraft, underwater vehicles, electrical motors, power systems, and automotive engines [11-25]. In [11], a novel integral sliding surface is introduced to achieve the control for a kind of system based on the LMI technique, with the more available stability condition compared to the conventional linear sliding surface. However, the system with delay is not included in its research yet. Hence, all of the above motivate our work.

In this paper, the problem on the SMC for a kind of delay dynamic system will be discussed. By utilizing Lyapunov stability theory and a linear matrix inequality technique, a new observer-based on delayed output feedback will be 
constructed. An integral sliding surface will be presented to realize the SMC of the system with the more available stability condition. Finally, some numerical examples will be included to demonstrate the validity of the proposed control method.

Notation used in this paper is fairly standard. Let $R^{n}$ be the $n$-dimensional Euclidean space, $R^{n \times m}$ represents the set of $n \times m$ real matrix, $*$ denotes the elements below the main diagonal of a symmetric block matrix, $\operatorname{diag}\{\}$ represents the diagonal matrix, the notation $A>0$ means that $A$ is the real symmetric and positive definite, $I$ denotes the identity matrix with appropriate dimensions, and $\|\cdot\|$ refers to the Euclidean vector norm.

\section{Problem Statement and Preliminaries}

In this paper, the following dynamic system is considered:

$$
\begin{gathered}
\dot{x}(t)=A x(t)+B x(t-l)+L u(t), \\
z(t)=C x(t-d),
\end{gathered}
$$

where $x(t) \in R^{n}$ is the system state, $u(t) \in R^{m}$ is the system input, $y(t) \in R^{l}$ is the system output, $l$ is discrete delay, $z(t)$ is the measurable feedback output, and $A, B, L, C$ are the system matrices with appropriate dimension.

Then, an observer of system (1) is built as follows:

$$
\begin{gathered}
\dot{\hat{x}}(t)=A \widehat{x}(t)+B \widehat{x}(t-l)+L u(t)+e^{A d} K[z(t)-C \widehat{x}(t-d)], \\
\dot{\hat{x}}(t-d)=A \widehat{x}(t-d)+B \widehat{x}(t-d-l)+L u(t-d) \\
+K[z(t)-C \widehat{x}(t-d)],
\end{gathered}
$$

where $\widehat{x}(t) \in R^{n}$ is the state vector, $K$ is the feedback control matrix, and $d$ is the measurable feedback delay.

Define the observation error:

$$
e(t)=x(t)-\widehat{x}(t) .
$$

The following theoretical result will be used throughout the paper.

Lemma 1. For observer (2), the following equation holds:

$$
\widehat{x}(t)=e^{A d} \widehat{x}(t-d)+\int_{t-d}^{t} e^{A(t-\tau)}(L u(\tau)+B \widehat{x}(\tau-l)) d \tau .
$$

Proof. The derivative of (4) is as follows:

$$
\begin{aligned}
\dot{\hat{x}}(t)= & e^{A d} \dot{\hat{x}}(t-d)+A \int_{t-d}^{t} e^{A(t-\tau)}(L u(\tau)+B \widehat{x}(\tau-l)) d \tau \\
& +L u(t)-e^{A d} L u(t-d)+B \widehat{x}(t-l) \\
& -e^{A d} B \widehat{x}(t-d-l) \\
= & e^{A d} \dot{\hat{x}}(t-d)+A\left(\widehat{x}(t)-e^{A d} \widehat{x}(t-d)\right) \\
& +L u(t)-e^{A d} L u(t-d)+B \widehat{x}(t-l) \\
& -e^{A d} B \widehat{x}(t-d-l)
\end{aligned}
$$

$$
\begin{aligned}
& =A \widehat{x}(t)+L u(t)+B \widehat{x}(t-l) \\
& +e^{A d}(\dot{\hat{x}}(t-d)-A \widehat{x}(t-d)-L u(t-d) \\
& \quad-B \widehat{x}(t-d-l)) .
\end{aligned}
$$

Consider (2), we get

$\dot{\hat{x}}(t)=A \widehat{x}(t)+B \hat{x}(t-l)+L u(t)+e^{A d} K[z(t)-C \widehat{x}(t-d)]$.

The proof of Lemma 1 is thus completed.

\section{Design of Observer}

Theorem 2. If there exists a matrix $M$, and positive-definite symmetric matrices $P$ and $Q$ satisfy

$$
\begin{gathered}
{\left[\begin{array}{cc}
Q+P A-M C+A^{T} P-C^{T} M^{T} & P B \\
* & -Q
\end{array}\right]<0,} \\
K=P^{-1} M
\end{gathered}
$$

then, observer (2) can realize the observation of system (1).

Proof. From system (1), we have

$$
\dot{x}(t-d)=A x(t-d)+B x(t-l-d)+L u(t-d) .
$$

With (2), we can get

$$
\dot{e}(t-d)=(A-K C) e(t-d)+B e(t-l-d) .
$$

Choose the Lyapunov functional candidate as

$$
V(t-d)=e^{T}(t-d) P e(t-d)+\int_{t-d-l}^{t-d} e^{T}(s) Q e(s) d s .
$$

The time derivative of $V(t-d)$ is

$$
\begin{aligned}
\dot{V}(t-d)= & 2 e^{T}(t-d) P \dot{e}(t-d) \\
& +e^{T}(t-d) Q e(t-d)-e^{T}(t-d-l) \\
& \times Q e(t-l-d) \\
= & 2 e^{T}(t-d) P((A-K C) e(t-d)+B e(t-l-d)) \\
& +e^{T}(t-d) Q e(t-d)-e^{T}(t-d-l) \\
& \times Q e(t-l-d) .
\end{aligned}
$$

Then, the following equation holds:

$$
\dot{V}(t-d)=\xi^{T}(t-d) \Xi \xi(t-d),
$$

where

$$
\begin{gathered}
\xi(t)=\left[e^{T}(t), e(t-l)\right]^{T}, \\
\Xi=\left[\begin{array}{cc}
P(A-K C)+(A-K C)^{T} P+Q & P B \\
* & -Q
\end{array}\right] .
\end{gathered}
$$


Let $M=P K$, and, with LMI (7), we can conclude

$$
\dot{V}(t-d)<0 \text {. }
$$

Hence,

$$
\lim _{t \rightarrow \infty} e(t-d) \longrightarrow 0
$$

From system (1), the following equation can be derived:

$$
x(t)=e^{A d} x(t-d)+\int_{t-d}^{t} e^{A(t-\tau)}(L u(\tau)+B \widehat{x}(\tau-l)) d \tau .
$$

Considering (4), we have

$$
e(t)=e^{A d} e(t-d)+\int_{t-d}^{t} e^{A(t-\tau)} B e(\tau-l) d \tau
$$

Finally, combined with (16), we can get $\lim _{t \rightarrow \infty} e(t) \rightarrow 0$, which means the realization of the observation. The proof of Theorem 2 is thus completed.

\section{Design of Sliding Motion Control Law}

First, we introduce the following integral sliding surface:

$$
\begin{aligned}
s(t)= & H x(t)-\int_{0}^{t} H(A+L N) x(\xi) d \xi \\
& -\int_{0}^{t} H B x(\xi-l(\xi)) d \xi .
\end{aligned}
$$

For system (1), we have

$$
x(t)=x(0)+\int_{0}^{t}(A x(\xi)+B x(\xi-l)+L u(\xi)) x(\xi) d \xi .
$$

Hence, the following equation holds:

$$
s(t)=H x(0)+H L \int_{0}^{t}(u(\xi)-N x(\xi)) d \xi .
$$

By $\dot{s}(t)=0$, we get the equivalent control law as

$$
u_{e q}(t)=N x(t) .
$$

When $u(t)=N x(t)$, we can obtain

$$
\dot{x}(t)=(A+L N) x(t)+B x(t-l) .
$$

Then, based on Lyapunov theory and LMI techniques, the following theoretical result is derived.

Theorem 3. If there exists a matrix $T$, and positive-definite symmetric matrices $F$ and $S$ satisfying

$$
\begin{gathered}
{\left[\begin{array}{cc}
A F+L T+F^{T} A^{T}+T^{T} L^{T}+S & B F \\
* & -S
\end{array}\right]<0,} \\
N=T^{-1} F
\end{gathered}
$$

then, dynamic system (23) is stable.
Proof. Choose the Lyapunov functional candidate as

$$
V_{1}(t)=x^{T}(t) S_{1} x(t)+\int_{t-l}^{t} x^{T}(s) S_{2} x(s) d s
$$

Then, the time derivative of $V_{1}(t)$ is as

$$
\begin{aligned}
\dot{V}_{1}(t)= & 2 x^{T}(t) S_{1} \dot{x}(t)+x^{T}(t) S_{2} x(t)-x^{T}(t-l) S_{2} x(t-l) \\
= & 2 x^{T}(t) S_{1}((A+L N) x(t-d)+B x(t-l)) \\
& +x^{T}(t) S_{2} x(t)-x^{T}(t-l) S_{2} x(t-l) .
\end{aligned}
$$

Hence, we have

$$
\dot{V}_{1}(t)=\xi^{T}(t) \Xi \xi(t),
$$

where

$$
\begin{gathered}
\xi(t)=\left[x^{T}(t), x(t-l)\right]^{T}, \\
\Xi=\left[\begin{array}{cc}
S_{1}(A+L N)+(A+L N)^{T} S_{1}+S_{2} & S_{1} B \\
* & -S_{2}
\end{array}\right] .
\end{gathered}
$$

Let $F=S_{1}^{-1}$; pre- and postmultiply $\Xi$ by $\operatorname{diag}\{F, F\}$; we have

$$
\Xi=\left[\begin{array}{cc}
(A+L N) F+F(A+L N)^{T}+F S_{2} F & B F \\
* & -F S_{2} F
\end{array}\right] .
$$

Let $S=F S_{2} F, T=N F$, and consider LMI (24); we can get

$$
\dot{V}_{1}(t)<0 \text {. }
$$

Hence, dynamic system (23) is stable. The proof of Theorem 3 is thus completed.

Next based on the above theoretical results, a sliding mode controller will be constructed to realize the stabilization of dynamic system (1).

Theorem 4. For dynamic system (1), the state trajectory will be driven onto the sliding surface $s(t)$ in a finite time by the following SMC law:

$$
u(t)=N \widehat{x}(t)-\eta \operatorname{sign}\left(H^{T} L^{T} s(t)\right),
$$

where $\eta$ and $\rho$ are positive scalars.

Proof. Choose the Lyapunov functional candidate as

$$
V_{2}(t)=\frac{1}{2} s^{T}(t) s(t) .
$$

With (21) and (32), we have

$$
\begin{aligned}
\dot{s}(t) & =H L(u(t)-N x(t)) \\
& =-H L \eta \operatorname{sign}\left(H^{T} L^{T} s(t)+N e(t)\right) .
\end{aligned}
$$




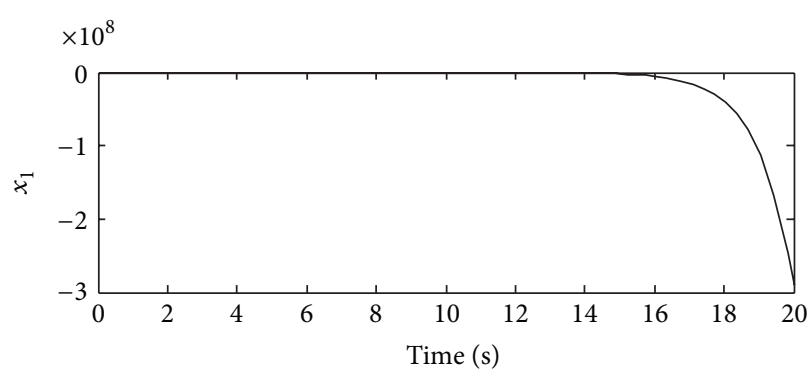

(a)

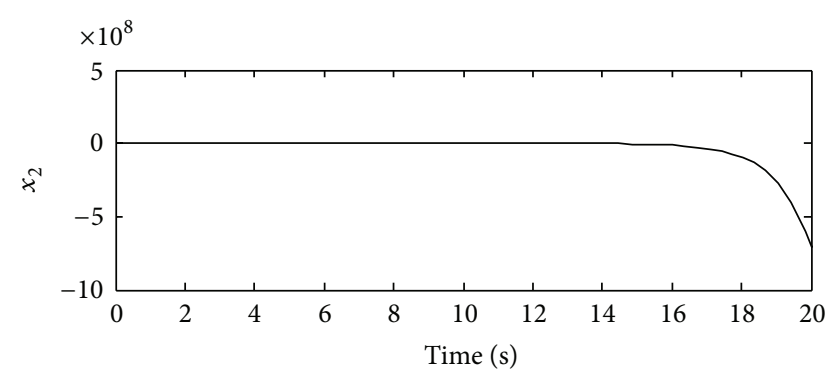

(b)

FIgURE 1: The time response of $x(t)$ of system (1) without SMC.

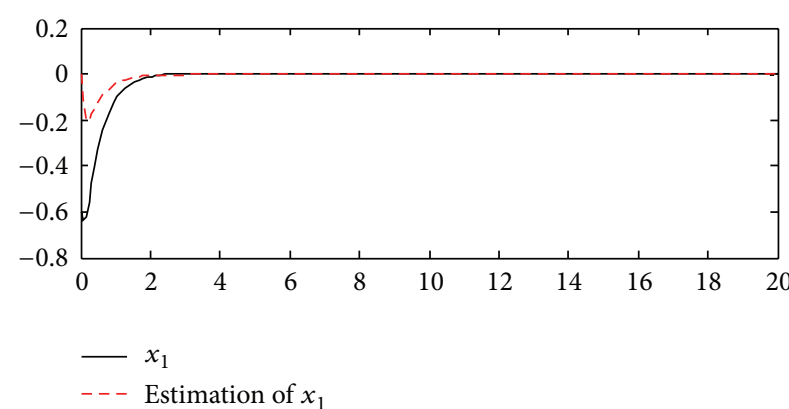

(a)

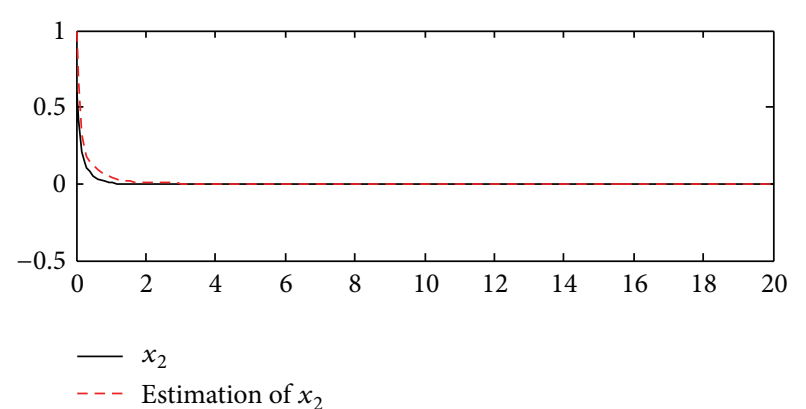

(b)

FIGURE 2: The time response of $x(t)$ and $\widehat{x}(t)$ of system (1) with SMC.

When the observation of system (1) is achieved, the time derivative of $V_{2}(t)$ is as

$$
\begin{aligned}
\dot{V}_{2}(t) & =s^{T}(t) \dot{s}(t) \\
& =-s^{T}(t) H L\left(\eta \operatorname{sign}\left(H^{T} L^{T} s(t)\right)\right) \\
& =-\eta\left\|N^{T} H^{T} L^{T} s(t)\right\| \leq 0 .
\end{aligned}
$$

Hence, the system state trajectory can converge to the sliding surface $s(t)$ and stay on the surface. This concludes the proof of Theorem 4 .

\section{Numerical Example}

In this section, we will verify the proposed theoretical theorems by giving some illustrative examples.

First consider dynamic system (1) with the following parameters:

$$
\begin{aligned}
& A=\left[\begin{array}{cc}
1 & 0.5 \\
0.5 & 0.8
\end{array}\right], \quad B=\left[\begin{array}{cc}
-0.5 & 0 \\
0.3 & -0.3
\end{array}\right], \quad L=\left[\begin{array}{cc}
0.8 & 0 \\
0 & 1.2
\end{array}\right], \\
& H=\left[\begin{array}{ll}
0.2 & 0.2
\end{array}\right], \quad C=\left[\begin{array}{ll}
1 & 1
\end{array}\right], \\
& d=2 s, \quad l=1 s, \quad \eta=0.5, \\
& x_{0}=[-0.6,0.6]^{T}, \quad \widehat{x}_{0}=[0,1.0]^{T} .
\end{aligned}
$$

Corresponding simulation results are shown in Figure 1.
Then, the presented observer-based SMC method in this paper is applied to system (1). Based on Theorem 3, we can get the control parameters as follows:

$$
N=\left[\begin{array}{ll}
-3.0937 & -0.1861 \\
-0.1837 & -2.9113
\end{array}\right], \quad K=\left[\begin{array}{l}
14.0436 \\
14.1551
\end{array}\right] .
$$

In addition, to avoid the chattering phenomenon of SMC, $\operatorname{sign}(s(t))$ is recommended to be replaced by $s(t) /(|s(t)|+$ $0.05)$, and the corresponding simulation results are shown in Figures 2 and 3.

Remark 5. From Figure 1, it can be seen that the state variables of the system diverge to zero as time passes by. This means that the considered system is not stable. Figure 2 shows the time response of system state $x(t)$ and system state estimate $\widehat{x}(t)$ based on the given observer-based SMC method. Figure 3 shows the time response of sliding mode control input $u(t)$. It can be seen that $\widehat{x}(t)$ converges to $x(t)$ during 4.0 seconds, and the original unstable dynamic system becomes stable for the utilization of our controller, which demonstrates the effectiveness of the presented theoretical results.

\section{Conclusion}

In this paper, the problem on the stabilization for a kind of dynamic system has been discussed. Through utilizing Lyapunov stability theory and linear matrix inequality techniques, a delayed output feedback observer has been designed, and a sliding mode controller has been constructed 


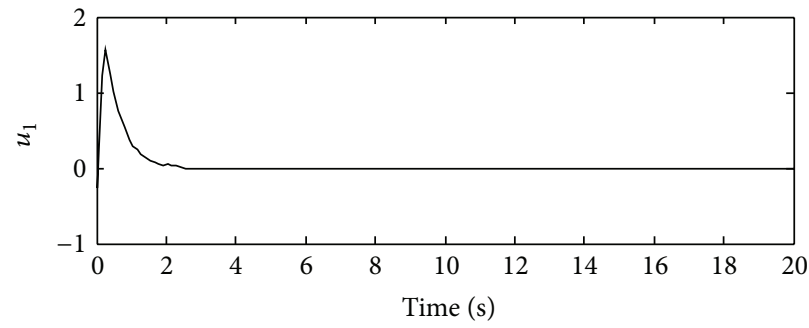

(a)

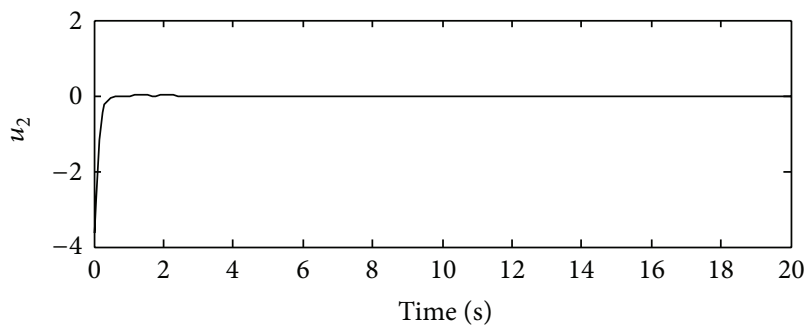

(b)

FIgURE 3: The time response of control input $u(t)$ of system (1).

to realize the stabilization of the system. Finally, some typical numerical examples have been included to verify the validity of the proposed SMC method.

\section{Conflict of Interests}

The authors declare that there is no conflict of interests regarding the publication of this paper.

\section{Acknowledgments}

This work was partially supported by the Key Projects of Xihua University (Z1120946), the National Key Basic Research Program, China (2011CB710706, 2012CB215202), the 111 Project (B12018), and the National Natural Science Foundation of China $(61174058,61134001)$.

\section{References}

[1] B. Zhou, Z.-Y. Li, and Z. Lin, "Observer based output feedback control of linear systems with input and output delays," Automatica, vol. 49, no. 7, pp. 2039-2052, 2013.

[2] A. Churilov, A. Medvedev, and A. Shepeljavyi, "A state observer for continuous oscillating systems under intrinsic pulse-modulated feedback," Automatica, vol. 48, no. 6, pp. 1117-1122, 2012.

[3] D. S. Laila, M. Lovera, and A. Astolfi, "A discrete-time observer design for spacecraft attitude determination using an orthogonality-preserving algorithm," Automatica, vol. 47, no. 5, pp. 975980, 2011.

[4] X. Wang, J. Liu, and K.-Y. Cai, "Tracking control for a velocitysensorless VTOL aircraft with delayed outputs," Automatica, vol. 45, no. 12, pp. 2876-2882, 2009.

[5] X. Zhang and Y. Lin, "Adaptive output feedback tracking for a class of nonlinear systems," Automatica, vol. 48, no. 9, pp. 23722376, 2012.

[6] B. Jiang, P. Shi, and Z. Mao, "Sliding mode observer-based fault estimation for nonlinear networked control systems," Circuits, Systems, and Signal Processing, vol. 30, no. 1, pp. 1-16, 2011.

[7] H. R. Karimi and P. Maass, "A convex optimization approach to robust observer-based $H_{\infty}$ control design of linear parametervarying delayed systems," International Journal of Modelling, Identification and Control, vol. 4, pp. 226-241, 2008.

[8] M. Liu, D. W. C. Ho, and Y. Niu, "Observer-based controller design for linear systems with limited communication capacity via a descriptor augmentation method," IET Control Theory \& Applications, vol. 6, no. 3, pp. 437-447, 2012.
[9] W.-J. Chang, C.-C. Ku, and P.-H. Huang, "Robust fuzzy control via observer feedback for passive stochastic fuzzy systems with time-delay and multiplicative noise," International Journal of Innovative Computing, Information and Control, vol. 7, no. 1, pp. 345-364, 2011.

[10] H. R. Karimi, "Observer-based mixed $H_{2} / H_{\infty}$ control design of linear systems with time-varying delays: an LMI approach," International Journal of Control, Automation and Systems, vol. 6, no. 1, pp. 1-14, 2008.

[11] L. Wu and D. W. C. Ho, "Sliding mode control of singular stochastic hybrid systems," Automatica, vol. 46, no. 4, pp. 779-783, 2010.

[12] M. Basin, L. Fridman, and P. Shi, "Optimal sliding mode algorithms for dynamic systems," Journal of the Franklin Institute, vol. 349, no. 4, pp. 1317-1322, 2012.

[13] Z. Lin, Y. Xia, P. Shi, and H. Wu, "Robust sliding mode control for uncertain linear discrete systems independent of timedelay," International Journal of Innovative Computing, Information and Control, vol. 7, no. 2, pp. 869-880, 2011.

[14] S. Qu, Z. Lei, Q. Zhu, and H. Nouri, "Stabilization for a class of uncertain multi-time delays system using sliding mode controller," International Journal of Innovative Computing, Information and Control, vol. 7, no. 7, pp. 4195-4205, 2011.

[15] L. Wu, X. Su, and P. Shi, "Sliding mode control with bounded $L_{2}$ gain performance of Markovian jump singular time-delay systems," Automatica, vol. 48, no. 8, pp. 1929-1933, 2012.

[16] P. Shi, Y. Xia, G. P. Liu, and D. Rees, "On designing of slidingmode control for stochastic jump systems," IEEE Transactions on Automatic Control, vol. 51, no. 1, pp. 97-103, 2006.

[17] M. Liu and P. Shi, "Sensor fault estimation and tolerant control for Itô stochastic systems with a descriptor sliding mode approach," Automatica, vol. 49, no. 5, pp. 1242-1250, 2013.

[18] Z. He, J. Wu, G. Sun, and C. Gao, "State estimation and sliding mode control of uncertain switched hybrid systems," International Journal of Innovative Computing, Information and Control, vol. 8, pp. 7143-7156, 2012.

[19] R. Yang, P. Shi, G.-P. Liu, and H. Gao, "Network-based feedback control for systems with mixed delays based on quantization and dropout compensation," Automatica, vol. 47, no. 12, pp. 2805-2809, 2011.

[20] L. Wu, P. Shi, and H. Gao, "State estimation and sliding-mode control of Markovian jump singular systems," IEEE Transactions on Automatic Control, vol. 55, no. 5, pp. 1213-1219, 2010.

[21] T.-C. Lin, S.-W. Chang, and C.-H. Hsu, "Robust adaptive fuzzy sliding mode control for a class of uncertain discrete-time nonlinear systems," International Journal of Innovative Computing, Information and Control, vol. 8, no. 1, pp. 347-359, 2012. 
[22] M. Liu, P. Shi, L. Zhang, and X. Zhao, "Fault-tolerant control for nonlinear Markovian jump systems via proportional and derivative sliding mode observer technique," IEEE Transactions on Circuits and Systems I, vol. 58, no. 11, pp. 2755-2764, 2011.

[23] H. R. Karimi, "A sliding mode approach to $H_{\infty}$ synchronization of master-slave time-delay systems with Markovian jumping parameters and nonlinear uncertainties," Journal of the Franklin Institute, vol. 349, no. 4, pp. 1480-1496, 2012.

[24] J. Zhang, P. Shi, and Y. Xia, "Robust adaptive sliding-mode control for fuzzy systems with mismatched uncertainties," IEEE Transactions on Fuzzy Systems, vol. 18, no. 4, pp. 700-711, 2010.

[25] M. Liu and G. Sun, "Observer-based sliding mode control for Itô stochastic time-delay systems with limited capacity channel," Journal of the Franklin Institute, vol. 349, no. 4, pp. 1602-1616, 2012. 


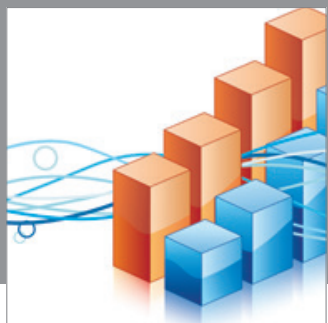

Advances in

Operations Research

mansans

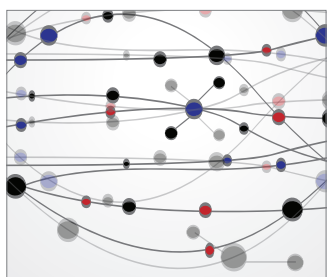

The Scientific World Journal
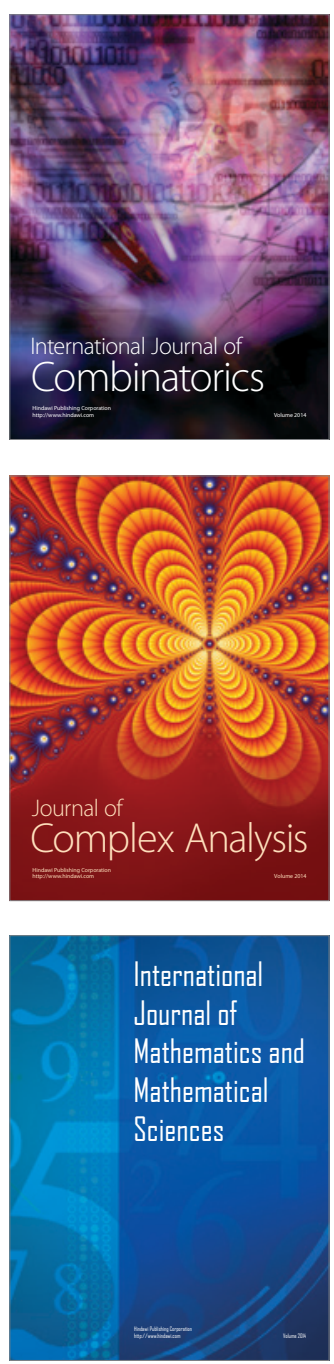
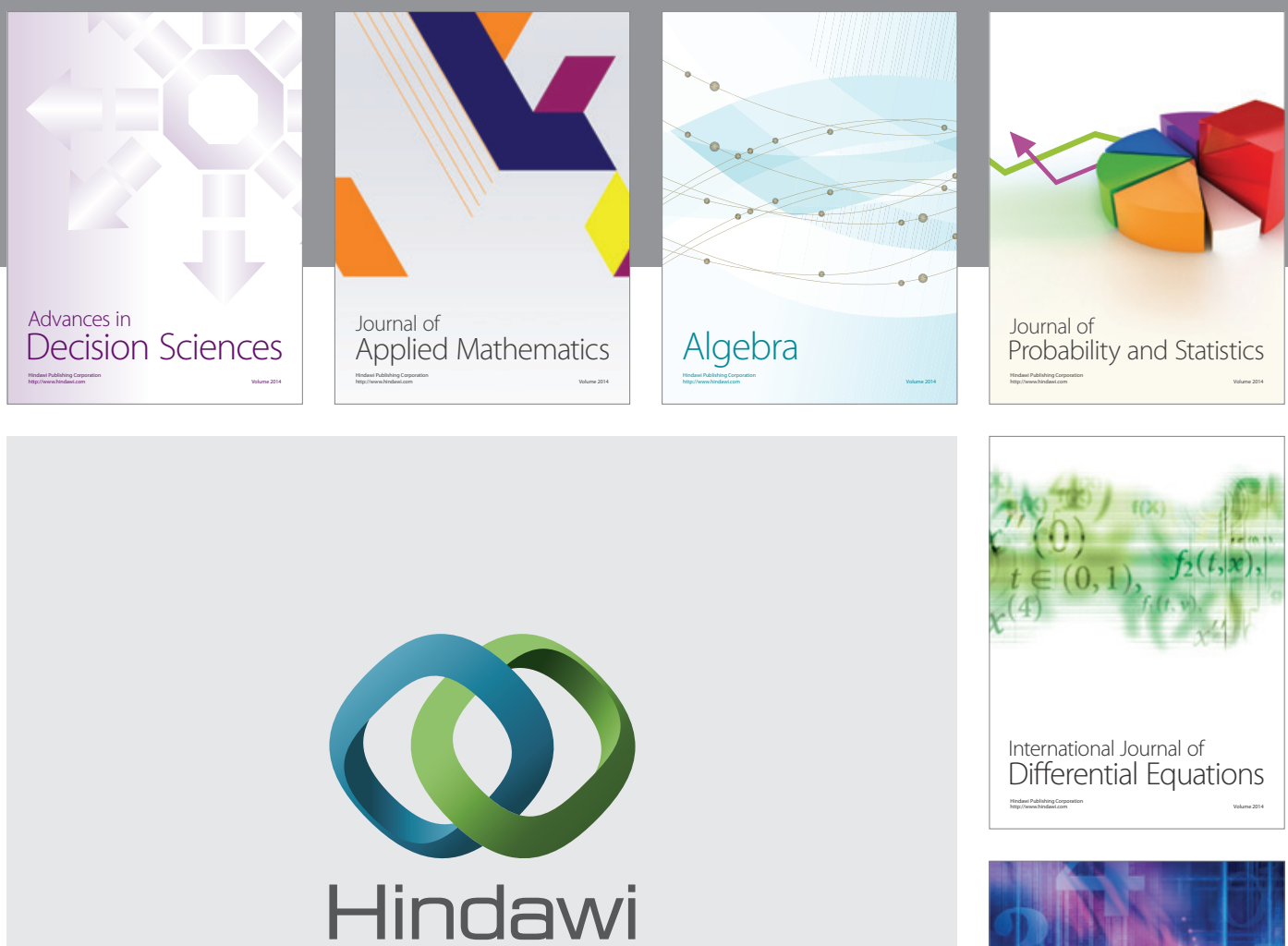

Submit your manuscripts at http://www.hindawi.com
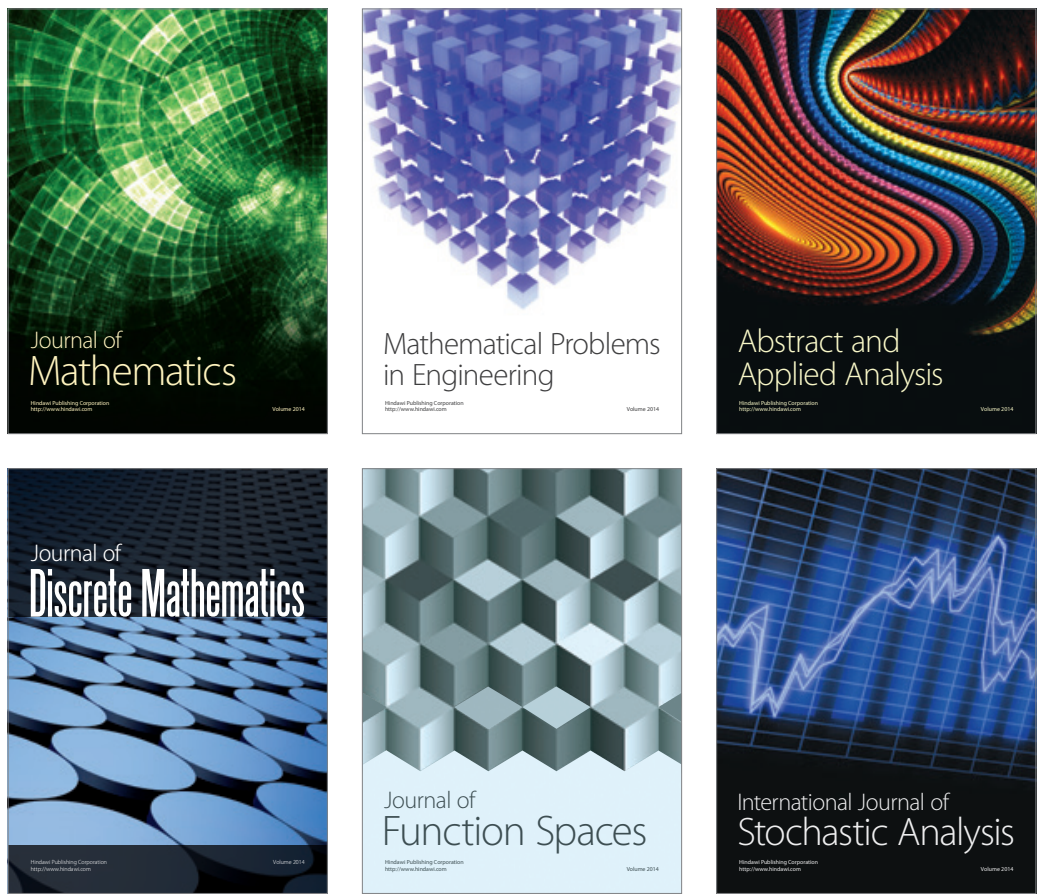

Journal of

Function Spaces

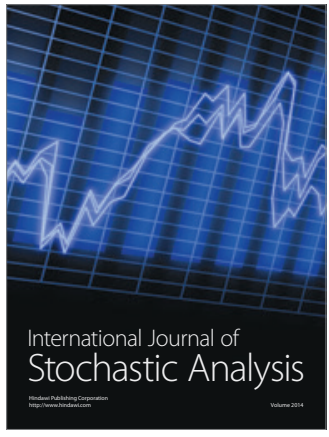

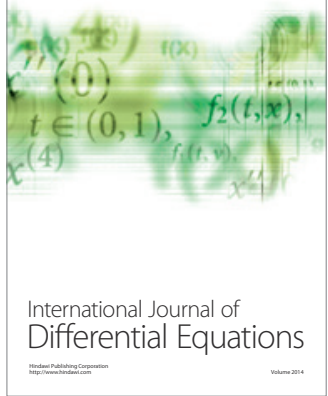
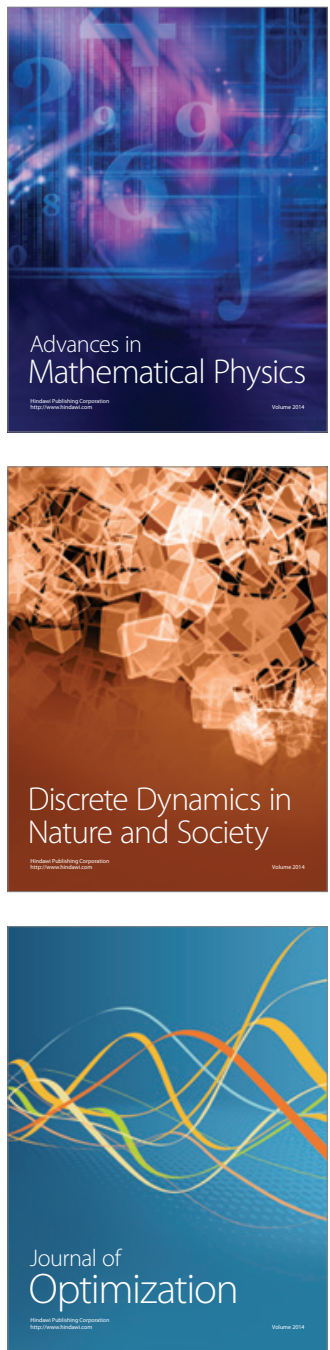